KeMAS 16 (3) (2021) 356-365
Jittp:/journal.unnes.ac.id/nju/index.php/kemas

\title{
Parental Monitoring and Risk Behavior in Middle Adolescents
}

Catharina Dara Gryselda ${ }^{1 \bowtie}$, Theresia Indira Shanti ${ }^{1}$

${ }^{1}$ Faculty of Psychology, Indonesian Catholic University of Atma Jaya, Jenderal Sudirman Street No. 51, South Jakarta, Jakarta, Indonesia.

\begin{tabular}{l} 
Article Info \\
\hline Article History: \\
Submitted February 2020 \\
Accepted May 2020 \\
Published March 2021 \\
\hline Keywords: \\
Middle adolescent, parent- \\
child relationship, parental \\
monitoring, risk behaviour \\
\hline DOI \\
https://doi.org/10.15294/ \\
kemas.v16i3.24341
\end{tabular}

\begin{abstract}
Friends played significant role due to middle adolescents tended to imitate behaviour of their friends including the risk behaviour. Parental monitoring could minimize the risk. However, the excessive unreasonable parental monitoring tended to increase risk behaviour of middle adolescents. Therefore, the purpose of this study was to know whether perceived parental monitoring had a significant relationship with risk behaviour among middle adolescents. This study used quantitative method with two measuring instruments in the form of a questionnaire, Parental Monitoring Questionnaire which consisted of 25 items to measure parental monitoring and Adolescence Risk Behaviour Questionnaire which consisted of 15 items to measure risk behaviour. The participants in this study were 105 male senior high school student age 15-17 years, who lived with both of their parents in Jakarta. Correlation test results showed that there was a significant relationship between perceived parental monitoring and substance use, premarital sex, and criminal behaviour among middle adolescents. Based on these results, the researcher presented some discussion materials and the suggestions that needed to be considered for further research.
\end{abstract}

\section{Introduction}

Statistical data has shown that the prevalence of risky behavior often appears during the developmental stage of adolescents, especially in adolescents who are in high school education and above (>14 years), such as smoking behavior, alcohol use, sexual activity, engaging in delinquency, acting criminally, and so on. (Schuster, Mermelstein, \& Wakschlag, 2013). Some of the risky behaviors of adolescents in Indonesia have shown a number that needs attention because they are alarming. One of the risky behaviors is smoking. The 2018 Basic Health Research (Riskesdas) found that the prevalence of smoking in people over 10 years old was 28.8 percent. In fact, the percentage of Indonesian adolescents aged $13-15$ years who smoke is $19.4 \%$, which is the highest among other ASEAN countries (data from the Southeast Asia Tobacco Control
Alliance in databoks.katadata.co.id). Another risky behavior is that 70 percent of teenagers start drinking alcohol from the age of 15-19 percent and women 58 percent. Meanwhile, other risky behavior, namely free sex behavior is not a strange thing in the life of Indonesian adolescents. In July 2019, 33 percent of adolescents in 5 major cities in Indonesia have had sexual intercourse before marriage, and $58 \%$ of them have penetrated between the ages of 18 and 20 (Liputan 6.com). Drug use during adolescence is associated with an increased risk of depression in young adulthood. Younger marijuana users (ages 14 to 15) had a significantly higher risk of suicidal behavior, although not overall (Gobby et al., 2019).

Many theories explain the factors that can cause or influence risky behavior in adolescents. One of the factors that influence adolescent risk behavior comes from the 
relationship between parents and adolescents. At this stage, the relationship between parents and children gradually becomes more equal or horizontal, so that adolescents feel they have a greater degree of autonomy and independence compared to the previous period (Parks in Tagliabue, Olivari, Giuliani, \& Confalonieri, 2018). This in turn can lead to conflicts between adolescents who begin to protect their privacy and their parents' desire to stay informed about the whereabouts of their teenagers (Petronio \& Caughlin, 2005; Hawk et al., 2009).

In adolescence, what might happen is an increase in alcohol consumption, it can happen based on their environment. This can occur in adolescents and new adults, which can interfere with long-term accumulated alcohol consumption, and often adolescents have higher levels of consumption (Carpenter et al., 2019), and tend to develop themselves to the limit of permitted behavior. Parental monitoring is defined as the knowledge of parents about the whereabouts, activities and relationships of their teenagers. In the context of risk factors, parental monitoring has shown a promotive and protective effect on adolescents. Apart from that, parental monitoring can also protect adolescents by resisting the effects of externalizing problems (Kelly et al., 2017). Suwarni (in Jatnika, 2017) explains, the unbalanced and excessive implementation of parental monitoring can actually contribute to risky behavior.

Previous research conducted by Stattin and Kerr (2000) tried to explain the relationship between parental monitoring and risk behavior in adolescents. The sample in this study focused on the early adolescent stage, namely Swedish teenagers aged 14 years and their parents. In this study, parental monitoring applied by parents to adolescents was measured using a youth report version of the questionnaire and the parents report. The results of this study indicate that parental monitoring has a significant relationship with risky behavior, such as delinquency, smoking, drug use and sexual activity. The results of this study also indicate that parental monitoring requires a two-way process, between the active role of parents (parental knowledge, parental solicitation and parental control), and the active role of children (adolescent disclosure). So not only parents play a role in parental monitoring, but teenagers themselves can also contribute to the successful process of parental monitoring.

On the other hand, previous research conducted by Stavrinides (2011) also tried to explain the relationship between parental monitoring and risky behavior in adolescents. The sample in this study focused on the early adolescence stage, namely adolescents aged 1415 years and their parents. In this study, parental monitoring that was applied by parents to adolescents was measured using a questionnaire version of the parents report. The results of this study indicate that parental monitoring does not have a significant relationship with risky behavior, such as delinquency, smoking, sexual activity and drug use.

Research by Stavrinides (2011), which measures parental monitoring from the point of view of parents, is deemed inappropriate. The meaning or perception of children towards parental monitoring carried out by parents itself has a much more important role because the success of parental monitoring does not only come from the active role of parents, but teenagers themselves can also contribute to the successful process of parental monitoring, by selecting information - what information do parents want to disclose or share. Adolescent's willingness to disclose information to parents is influenced by adolescent perceptions of monitoring or supervision carried out by the parents themselves (parental monitoring).

If parental monitoring is perceived by adolescents as a form of parental support that provides comfort because it shows someone who cares and cares about them, then the willingness of adolescents to disclose information to parents tends to be high (Diclemente, Wingwood, Crosby, Sionean, Cobb, Harrington, \& Oh, 2001). In this situation, parental monitoring can be used as an effort to minimize risky behavior. Based on the explanation above, it can be concluded that one of the important things in parental monitoring is the adolescent's perception of the supervision or monitoring of activities carried out by the parents themselves (Diclemente, Wingwood, Crosby, Sionean, Cobb, Harrington, \& Oh, 2001). Walgito (2010) defines perception as an 
individual process to organize and interpret stimuli received through the senses. Based on this explanation, the perception of parental monitoring can be defined as an individual process, which in this study is adolescents to choose, organize and interpret the actions of parents to carry out supervision, which can be done by gaining knowledge about the activities or whereabouts of children, and also using rules to limit children's behavior.

In this study, parental monitoring will focus on how parents can get information about the activities and existence of adolescents directly, by involving the active role of parents (parental knowledge, parental solicitation and parental control), and the active role of children (adolescent disclosure). In this study, parental monitoring applied by parents to adolescents is then perceived and measured from the adolescent's point of view using a youth report version of the questionnaire. The reason the researchers conducted this study was because many parental monitoring studies only involved the active role of parents as an effort that could be made to obtain information about the activities and whereabouts of adolescents directly. Research that discusses and includes the role of adolescents in parental monitoring is rarely found in the parental monitoring literature. Whereas as explained above, the success of parental monitoring does not only come from the active role of the parents, but the teenagers themselves can also contribute to the successful process of parental monitoring.

\section{Method}

Data collection was carried out quantitatively, namely correlational, from March to June 2019. The purpose of this study was to see whether there was a significant relationship between parental monitoring and risk behavior in middle adolescence or not. In this study, researchers found 105 participants who fit the criteria and were willing to participate. The sample characteristics for this study were male adolescents aged 15-17 years, high school students or equivalent, residing in the Jakarta area, and living with both of their parents. The sampling technique used in this study is a non-probability sampling technique, which is a sampling technique that is not randomly selected (Creswell, 2012). The nonprobability sampling approach that researchers used in this study was convenience sampling. Creswell (2012) explains that the research participants who were selected to be the sample could be due to coincidence or other factors that the researcher had planned. In this study, researchers will only take people within the reach of the researchers, who can be contacted, according to their characteristics and willing to participate.

Parental Monitoring Questionnaire (PMQ), this was done by adapting and modifying the youth-report version of the Parental Monitoring Questionnaire scale that was first compiled by Stattin and Kerr in 2000 (Stattin \& Kerr, 2000; Kerr, Stattin, and Burk, 2010; Stattin and Kerr in Hamza and Willoughby, 2011; Stattin \& Kerr in Everri, Tiziana, \& Fruggeri, 2015). This instrument consists of 25 items that are used to assess the four dimensions of parental monitoring, namely: parental knowledge, adolescence disclosure, parental control, and parental solicitation. Cronbach's alpha values for the PMQ dimensions range from .900 to 0.949 . The validity tests used in this measuring instrument are the content validity by means of expert judgment and construct validity. The construct validity technique used was internal consistency validity. In this validity test, researchers used Spearman correlation because the data obtained were not normally distributed. Racz \& McMahon (2011) explains, an item is declared valid if it has a corrected item total correlation value at least equal to 0.2 . The corrected itemtotal correlation PMQ values ranged from .541 to .934 .

PMQ measuring instrument uses a 5-point Likert Scale, with the following specifications: 1 (strongly disagree) and 5 (strongly agree), which is one type of summative scale. This means that the responses of all items will be added up to determine the final score of parental monitoring as perceived by middle adolescence. Middle adolescence who gets high scores perceives that they get supervision from their parents. Meanwhile, middle adolescence with low scores perceives themselves as not getting enough parental supervision. Adolescence Risk Behavior Questionnaire 
(ARBQ), it done by making their own measuring tool, namely ARBQ (Adolescence Risk Behavior Questionnaire), which is used to measure the frequency of adolescent behaviors and actions that have the potential to have a negative impact on individual health and well-being such as the use of illegal substances (smoking, alcohol, and drugs), premarital sex, and criminal behavior. There are 17 items used to assess three aspects of risky behavior, namely: substance use behavior, premarital sex behavior, and criminal behavior. The items that the researcher asked about on this measuring instrument have been adjusted to the behaviors that are mostly categorized as risky behaviors that were carried out during Indonesian adolescence, especially those living in big cities like Jakarta.

Cronbach's alpha values for aspects of the ARBQ range from .808 to .962 . The validity tests used in this measuring instrument are the content validity by means of expert judgment and construct validity. The construct validity technique used was internal consistency validity. In this validity test, researchers used Spearman correlation because the data obtained were not normally distributed. Racz \& McMahon (2011) explains, an item is declared valid if it has a corrected item total correlation value at least equal to 0.2 . The corrected itemtotal correlation ARBQ values range from .000 to .955 . Items which have a validity value of 0.000 are associated with homicide and rape behavior. In the measuring instrument trial, there were no study participants who reported having committed murder and rape behavior, so the researcher decided to delete the two items so that the total item of the ARBQ measuring instrument became 15 items.

The ARBQ measuring instrument uses a 5-point Likert-Scale, with the following specifications: 1 (never done) and 5 (always done), which is one type of summative scale. That is, the responses of all items will be added up to determine the final score of the frequency of risky behavior carried out by middle adolescence.

The method of scoring the ARBQ measuring instrument can be done by adding up all the respondents' answers on each aspect. So that it will produce three total scores because this measuring instrument measures three aspects separately, namely substance uses behavior, premarital sex behavior, and criminal behavior. Middle adolescence with high scores has a higher tendency to engage in risky behavior in certain aspects. Meanwhile, middle adolescence with low scores has a lower tendency to engage in risky behavior in certain aspects. The data analysis method that researchers will use is the correlation statistical technique. This statistical correlation technique is used to determine the relationship between two variables (Gravetter and Wallnau, 2013).

\section{Results and Discussion}

Researchers found as many as 105 male adolescents aged 15-17 years who live with their parents in the Jakarta area. Researchers collected data using a questionnaire that has been distributed by researchers online. Data collection was carried out from June 4, 2019 to June 17,2019 . The following is an overview of the demographic data of the 105 study participants.

Table 1. Participant Demographic Data $(\mathrm{N}=105)$

\begin{tabular}{lcc}
\hline Category & Total & $\%$ \\
\hline Ages & & \\
15 years old & 21 & $20.00 \%$ \\
16 years old & 33 & $31.43 \%$ \\
17 years old & 51 & $48.57 \%$ \\
Residence Area & & \\
North Jakarta & 14 & $13.33 \%$ \\
East Jakarta & 27 & $25.71 \%$ \\
South Jakarta & 23 & $21.90 \%$ \\
West Jakarta & 20 & $19.05 \%$ \\
Central Jakarta & 21 & $20.00 \%$ \\
\hline
\end{tabular}




\begin{tabular}{lcc}
\hline Substance Use Behavior & & \\
$\quad$ Ever Did it & 56 & $53.33 \%$ \\
$\quad$ Never Did it & 49 & $46.67 \%$ \\
Premarital Sexual Behavior & & \\
$\quad$ Ever Did it & 38 & $36.19 \%$ \\
$\quad$ Never Did it & 67 & $63.81 \%$ \\
Criminal Behavior & & \\
Ever Did it & 102 & $97.14 \%$ \\
$\quad$ Never Did it & 3 & $2.86 \%$ \\
\hline
\end{tabular}

Based on the age category, from a total number of 105 participants who filled out the questionnaire, the most age category was at the age of 17 , which was $48.57 \%$. Then followed by participants at the age of 16 , namely $31.43 \%$ and finally at the age of 15 , which was $20.00 \%$. On the other hand, based on the category of residence area, from the total number of participants of 105 people who filled out the questionnaire, the category of residential area was mostly domiciled in East Jakarta, namely $25.71 \%$. This was followed by participants domiciled in South Jakarta, namely $21.90 \%$ and the least number of participants domiciled in North Jakarta, namely $13.33 \%$. The Ministry of Health of the Republic of Indonesia explains that adolescents at risk are adolescents who have engaged in risky behavior, such as using illegal substances and having premarital sex (Department of health, 2003). In table 4.1, it can be seen from the 105 study participants, 53.33\% had used substance use behavior, $36.19 \%$ had used premarital sex behavior, and $97.14 \%$ had committed criminal behavior. If calculated as a whole, as many as $102(97.14 \%)$ study participants were adolescents at risk because they had committed at least one form of risky behavior.

This study intends to see whether there is a significant relationship between perceptions of parental monitoring and middle adolescence risk behavior using statistical correlation methods. Before conducting a correlation test, it is necessary to do a normality test to see to what extent the distribution of the research variables has followed the normal distribution curve or not. If the data is normally distributed, the researcher must perform a parametric test. If the data is not normally distributed, the researcher must perform a nonparametric test (Wallnau \& Gravetter, 2013). The following are the results of the normality test that has been carried out.

Table 2. Results of Normality Test of Research Variables

\begin{tabular}{lcc} 
& \multicolumn{2}{c}{ Saphiro-Wilk } \\
\cline { 2 - 3 } & Statistic & Sig. \\
\hline Parental Monitoring & .941 & .000 \\
Substance Use Behavior & .759 & .000 \\
Premarital Sex Behavior & .619 & .000 \\
Criminal Behavior & .918 & .000 \\
\hline
\end{tabular}

Table 2 is a table of the results of the normality test for research variables. The Saphiro-Wilk significance value that needs to be fulfilled so that the data can be said to be normally distributed is $\mathrm{p}>.05$ (Gravetter \& Wallnau, 2013). Based on this test, it can be concluded that parental monitoring data, substance use behavior, premarital sex behavior, and criminal behavior are not normally distributed, so that the Spearman correlation technique will be used to examine the relationship between parental monitoring and substance use behavior, premarital sex behavior, and criminal behavior. 
Table 3. Correlation Results of Spearman Parental Monitoring and Risk Behavior

\begin{tabular}{llc}
\hline & & Parental Monitoring \\
\hline \multirow{2}{*}{ Parental Monitoring } & Correlation Coefficient & 1.000 \\
& Sig. (2-tailed) & \\
Substance Use Behavior & Correlation Coefficient & $-.623^{* *}$ \\
& Sig. (2-tailed) & .000 \\
Premarital Sex Behavior & Correlation Coefficient & $-.620^{* *}$ \\
& Sig. (2-tailed) & .000 \\
Criminal Behavior & Correlation Coefficient & $-.659^{* *}$ \\
& Sig. (2-tailed) & .000 \\
\hline
\end{tabular}

**Correlation is significant at the 0.01 level (2-tailed)

Based on Table 3 above, it can be seen that the perception of parental monitoring has a significant relationship with the behavior of substance use in middle adolescence, rs(103) $=-.623, \mathrm{p}<.05$; premarital sexual behavior, $\operatorname{rs}(103)=-.620, \mathrm{p}<.0 .5$; and criminal behavior, $\mathrm{rs}(103)=-.659, \mathrm{p}<.05, \mathrm{r} 2=.08$ middle adolescence. Keijers (2015) explains that the Parental Monitoring Questionnaire which is adapted from Stattin and Kerr (2000) can be used by researchers with the use of a full scale or only part of the dimensions of the scale, adjusted to the research objectives (Racz \& McMahon, 2011). Therefore, in this study, researchers will also look at the relationship between the dimensions of parental monitoring and risky behavior. The aim is to find out what dimensions of parental monitoring have the largest and smallest correlation coefficients.

Table 4. Correlation Results of Spearman Dimensions of Parental Monitoring and Risk Behavior

\begin{tabular}{|c|c|c|}
\hline & & Substance Use Behavior \\
\hline \multirow{2}{*}{ Parental Knowledge } & Correlation Coefficient & $-.619^{\star \star}$ \\
\hline & $N$ & 105 \\
\hline \multirow{2}{*}{ Adolescence Disclosure } & Correlation Coefficient & $-.607^{\star *}$ \\
\hline & $N$ & 105 \\
\hline \multirow{2}{*}{ Parental Control } & Correlation Coefficient & $-.649^{\star *}$ \\
\hline & $N$ & 105 \\
\hline \multirow{3}{*}{ Parental Solicitation } & Correlation Coefficient & $-.506^{* *}$ \\
\hline & $N$ & 105 \\
\hline & & Premarital Sex Behavior \\
\hline \multirow{2}{*}{ Parental Knowledge } & Correlation Coefficient & $-.617^{\star \star}$ \\
\hline & $N$ & 105 \\
\hline \multirow{2}{*}{ Adolescence Disclosure } & Correlation Coefficient & $-.644^{\star *}$ \\
\hline & $N$ & 105 \\
\hline \multirow{2}{*}{ Parental Control } & Correlation Coefficient & $-.591^{\star *}$ \\
\hline & $N$ & 105 \\
\hline \multirow{3}{*}{ Parental Solicitation } & Correlation Coefficient & $-.522^{\star *}$ \\
\hline & $N$ & 105 \\
\hline & & Criminal Behavior \\
\hline \multirow{2}{*}{ Parental Knowledge } & Correlation Coefficient & $-.668^{\star *}$ \\
\hline & $N$ & 105 \\
\hline \multirow{2}{*}{ Adolescence Disclosure } & Correlation Coefficient & $-.638^{\star *}$ \\
\hline & $N$ & 105 \\
\hline \multirow{2}{*}{ Parental Control } & Correlation Coefficient & $-.654^{\star *}$ \\
\hline & $N$ & 105 \\
\hline \multirow{2}{*}{ Parental Solicitation } & Correlation Coefficient & $-.497^{\star *}$ \\
\hline & $N$ & 105 \\
\hline
\end{tabular}

**Correlation is significant at the 0.01 level (2-tailed) 
Based on Table 4 above, the researcher found that the parental control dimension is one of the dimensions of parental monitoring that has the greatest correlation coefficient with substance use behavior in middle adolescence. $\left(r_{-}(s(103))=-.649, p<.05\right)$. Meanwhile, the dimension that has the smallest correlation coefficient with substance use behavior is the dimension of parental solicitation $\left(\mathrm{r}_{-}(\mathrm{s}(103))=\right.$ $-.506, \mathrm{p}<.05)$. Researchers also found that the dimension of disclosure adolescence is one of the dimensions of parental monitoring that has the greatest correlation coefficient with premarital sex behavior in middle adolescence. $\left(r_{-}(s(103))=-.644, p<.05\right)$. Meanwhile, the dimension that has the smallest correlation coefficient with premarital sex behavior is the dimension of parental solicitation $\left(\mathrm{r}_{-}(\mathrm{s}(103))=\right.$ $-.522, \mathrm{p}<.05)$. Finally, on criminal behavior, researchers found that the parental knowledge dimension is one of the dimensions of parental monitoring that has the greatest correlation coefficient with criminal behavior in middle adolescence. $\left(r_{-}(s(103))=-.668, p<.05\right)$. Meanwhile, the dimension that has the smallest correlation coefficient with criminal behavior is the dimension of parental solicitation ( $\mathrm{r}_{-}$ $(\mathrm{s}(103))=-.497, \mathrm{p}<.05)$.

Based on the research results that have been presented, it is known that 102 (97.14\%) of the study participants were adolescents at risk because they had committed at least one form of risky behavior. So it can be concluded that risky behavior in adolescents aged 15-17 years is quite common in adolescents who are participants in this study. The risky behaviors that are often carried out include: Substance use behavior, premarital sex behavior, and criminal behavior. Researchers assume that the high number of adolescents, who engage in risky behavior in this study, can be caused by the researchers controlling the factors that can cause adolescents to engage in risky behavior, such as age, gender, education, and area of residence. Efforts are needed to prevent adolescents from engaging in risky behavior. One of them is through familybased interventions, especially parents who are the first and foremost figures in influencing children's growth and development, which can be done by doing parental monitoring.
The results showed that parental monitoring had a significant relationship with risky behavior, both substance use behavior, sexual behavior, and criminal behavior. Furthermore, the researchers found that there was a significant negative relationship between parental monitoring and risky behavior, both substance use behavior, sexual behavior, and criminal behavior carried out in middle adolescence. Based on these results, the researchers concluded that parental monitoring can be used as an effort to minimize risky behavior. This is also found in other research on parental monitoring which explains that parental monitoring with risky behavior itself can be negatively related, meaning that adolescents with high parental supervision engage in less risky behavior and vice versa, adolescents who lack supervision tend to be antisocial, involved in delinquency, and acting criminally (Tralle in Suwarni, 2009; Huang, Murphy \& Hser, 2011; Racz \& McMahon, 2011; Sasson \& Mesch, 2014).

Researchers assume parental monitoring and risky behaviors have a significant negative relationship because parents use direct strategies that adolescents realize when doing parental monitoring, such as limiting adolescent actions with rules and asking where adolescents are. Parental monitoring carried out by parents is perceived by teenagers as a form of support that provides comfort because someone cares and cares for them. On the other hand, Sieverding, Adler, Witt, and Ellen (2005) argue that a higher level of parental monitoring can be associated with a lower level of risky behavior because: First, parental monitoring is perceived and perceived by adolescents, with the aim of limiting the scope of opportunities available for adolescents to engage in risky behavior. Second, parental monitoring creates an environment, where there is pressure on adolescents, so that adolescents obey what parents expect. Third, parental monitoring limits the scope of adolescents to their high-risk peers' social environment, so as to minimize adolescent perceptions of risky behavior that their peers might consider normal.

Diclemente, Wingwood, Crosby, Sionean, Cobb, Harrington, and Oh (2001) explained that parental monitoring which is negatively 
related to risky behavior makes adolescent's willingness to disclose information to parents tends to be high. This statement is supported by Stattin \& Kerr (2000) in their research, which also argues that the four domains of parental monitoring are parental knowledge, adolescence disclosure, parental control, and parental solicitation. Adolescence disclosure is a dimension of parental monitoring that has the greatest correlation coefficient with risky behavior.

This does not really agree with the results of the additional analysis that the researchers conducted. Based on the results of additional analysis between the dimensions of parental monitoring and aspects of risky behavior, the adolescence disclosure dimension has the greatest correlation coefficient only with premarital sex behavior. However, this does not happen for other risky behaviors, such as substance use behavior or criminal behavior. However, adolescence disclosure still has a large correlation coefficient with other risky behaviors.

On the other hand, parental solicitation is a dimension of parental monitoring that has the smallest correlation coefficient with risky behavior. Parental solicitation is related to how parents seek information about their children through various sources. The way parents seek this information can be done secretly, without permission or knowledge, such as eavesdropping on teenagers' conversations with other people, opening messages without permission, checking things secretly, or asking teenagers directly. The unbalanced and inaccurate way in which parents seek information about their child can frustrate teens because they lose control of their own privacy and cause feelings of discomfort. As a result, adolescents tend to complain because their parents are too involved in their lives and make them more likely to close themselves.

The explanation above shows that the creation of good parental monitoring can be done through cooperation between parents, families, and us. So it can be concluded that the success of parental monitoring does not only come from the active role of parents, but teenagers themselves can also contribute to the success of parental monitoring by choosing what information they want to disclose or tell parents. The openness of children to parents will help parents to have knowledge about the whereabouts and activities of their children.

There are deficiencies that may be corrected in future studies. First, the use of questionnaires via google form which is considered practical and can reach a wider variety of participants. In practice, there are several things that cannot be controlled if data collection is carried out using Google Form, such as whether or not the participant completes the questionnaire with the specified characteristics, as well as the situation and condition when the participant takes the test. Second is the lack of participants. Barlett, Kotrlik, and Higgins (2001) explain that the calculation table for the minimum number of samples taken in a population of over 10,000 is 119 people. In this study, researchers only managed to collect 105 participants. Third, the researchers did not consider asking some demographic data that might affect such as the occupation of parents, dating history, ethnicity, and the frequency of time adolescents spend doing activities with their families, especially their parents.

\section{Conclusion}

Based on the analysis of data collected from 105 participants regarding the relationship between perceptions of parental monitoring and risk behavior in male middle adolescence, the following results were obtained: (1) There is a significant relationship between parental monitoring and substance abuse behavior carried out in middle adolescence; (2) There is a significant relationship between parental monitoring and premarital sex behavior carried out in middle adolescence; (3) There is a significant relationship between parental monitoring and criminal behavior carried out in middle adolescence. There are methodological suggestions that can be made in further research. First, further research is expected to be able to take research samples randomly and in larger numbers, so that the research results can represent the population being studied. Second, further research is expected to include several broader and more complex aspects so that the results obtained can be more varied, 
such as comparing parental monitoring carried out by fathers and mothers, or testing the effect of parental monitoring and peer behavior with risky behavior, which one gives greater influence for adolescents. Finally, consider controlling for some of the characteristics of participants that might influence the study results, such as parental occupation, dating history, ethnicity, and family situation.

There are practical suggestions that can be made based on this research. First, parents are expected to be the main role models who are considered more experienced to be able to provide direction and support that helps adolescents solve problems, such as providing emotional support when adolescents are experiencing stress or when adolescents are having difficulty preventing adolescents from doing risky behavior. Second, parents are expected to cooperate in supervising their adolescents as early as possible. Not only by knowing and monitoring activities, but also conveying clear rules and boundaries. Finally, adolescents are expected to be able to open up with their parents, because good parental monitoring can be done through cooperation between parents, families, and ourselves. By opening up to parents, parents can always monitor and direct their adolescents when engaging in risky behavior.

\section{References}

Bartlett, J.E., Kotrlik, J.W., \& Higgins, C.C., 2001. Organizational Research: Determining Appropriate Sample Size in Survey Research. Information Technology, Learning, and Performance Journal, 19, pp.43-50.

Carpenter, R.W., Padovano, H.T., Emery, N.N., \& Jr, R.M., 2019. Rate of Alcohol Consumption in the Daily Life of Adolescents and Emerging Adults. Psychopharmacology, 236(11), pp.3111-3124.

Creswell, J.W., 2012. Educational Research: Planning, Conducting, and Evaluating Quantitative and Qualitative Research (4th ed.). Boston, MA: Pearson.

Diclemente, R.J., Wingood, G.M., Crosby, R., Sionean, C., Cobb, B.K., Harrington, K., \& Oh, M.K., 2001. Parental Monitoring: Association with Adolescents Risk Behaviors. Pediatrics, 107(6), pp.1363-1368.

Everri, M., Mancini, T., \& Laura, F., 2016. Disentangling Parental Monitoring: The
Role of Family Communication in Achieving Parental Knowledge. Psicologia Sociale, 11(3), pp.245-262.

Forman-Alberti, A.B., 2016. Relations Among Children's Impulsivity, Planning, and Social Stress in Predicting Adolescent Risky Behavior: A Longitudinal Approach. ProQuest Dissertations and Theses Database. UMI number: 10194734.

Gobbi, G., Atkin, T., Zytynski, T., Wang, S., Askari, S., Boruff, J., Ware, M., Marmorstein, N., Cipriani, A., Dendukuri, N., \& Mayo, N., 2019. Association of Cannabis Use in Adolescence and Risk of Depression, Anxiety, and Suicidality in Young Adulthood: A Systematic Review and Meta-analysis. JAMA Psychiatry, 76(4), pp.426-434.

Hamza, C.A., \& Willoughby, T., 2011. Perceived Parental Monitoring, Adolescent Disclosure, and Adolescent Depressive Symptoms: A Longitudinal Examination. Journal of Youth and Adolescence, 40, pp.902-915.

Hawk, S.T., Keijsers, L., Hale, W.W., \& Meeuws, W., 2009. Mind Your Own Business! Longitudinal Relations Between Perceived Privacy Invasion and Adolescent-parent Conflict. Journal of Family Psychology, 23, pp.511-520.

Huang, D.Y., Murphy, D.A., \& Hser, Y.I., 2011. Parental Monitoring During Early Adolescence Deters Adolescent Sexual Initiation: Discrete-time Survival Mixture Analysis. Journal of Child and Family Studies, 20(4), pp.511-520.

Keijsers, L., Frijns, T., Branje, S.J.T., \& Meeus, W., 2009. Developmental Links of Adolescent Disclosure, Parental Solicitation, and Control with Delinquency: Moderation by Parental Support. Developmental Psychology, 45(5), pp.1314-1327.

Kelly, M.L., Becker, S.J., \& Spirito, A., 2017. Parental Monitoring Protects Against the Effects of Parent and Adolescent Depressed Mood on Adolescent Drinking. Addictive Behaviors, 75, pp.7-11.

Kerr, M., Stattin, H., \& Tilton-Weaver, L., 2010. Parental Monitoring: A Critical Examination of Research. In V. Guilamo-Ramos, J. Jaccard \& P. Dittus (Eds.), Parental Monitoring of Adolescents: Current Perspectives for Researchers and Practioners. New York: Columbia Univeristy Press.

Petronio, S., \& Caughlin, J. P., 2005. Communication Privacy Management Theory: Understanding Families. In D. Braithwaite, \& L. Baxter (Eds.), Engaging theories in family communication: 
Multiple perspectives (pp. 35-49). Thousand Oaks: Sage.

Racz, S.J., \& McMahon,R.J., 2011. The Relationship Between Parental Knowledge and Monitoring to Child and Adolescent Conduct Problems: A 10-year Update. Clin. Child Family Psychol., 14, pp.377-398.

Ryan, J., Roman, N.V., \& Okwany, A., 2015. The Effects of Parental Monitoring and Communication on Adolescent Substance Use and Risky Sexual Activity: A Systematic Review. The Open Family Studies Journal, 7(1), pp. 12-27.

Sasson, H. \& Mesch, G.S., 2014. Parental Mediation, Peer Norms and Risky Online Behaviors Among Adolescents. Computers in Human Behavior, 33, pp.32-38.

Schuster, R., Mermelstein, M., \& Wakschlag,
L., 2013. Gender-specific Relationships Between Depressive Symptoms, Marijuana Use, Parental Communication and Risky Sexual Behavior in Adolescence. J Youth Adolescence, 42(1), pp.1194-1209.

Stattin, H., \& Kerr, M., 2000. Parental Monitoring: A Reinterpretation. Child Development, 71(4), pp.1072-1085.

Stavrinides, P., 2011. The Relationship Between Parental Knowledge and Adolescent Delinquency: A Longitudinal Study. International Journal about Parents in Education, 5(1), pp.46-55.

Tagliabue, S., Olivari, M.G., Giuliani, C., \& Confalonieri, E., 2018. To Seek or Not to Seek Advice: Talking About Romantic Issues During Emerging Adulthood. Europe's Journal of Psychology, 14(1), pp.125-142. 